\title{
Development of a World Health Organization mental health in schools programme in the Eastern Mediterranean Region
}

\author{
Hesham M. Hamoda, ${ }^{1}$ Sharon Hoover, ${ }^{2}$ Jeff Bostic, ${ }^{3,4}$ Atif Rahman ${ }^{5}$ and Khalid Saaed ${ }^{6}$
}

${ }^{1}$ Department of Psychiatry, Boston Children's Hospital and Harvard Medical School, Boston, MA, United States of America (Correspondence to: H. Hamoda: Hesham.Hamoda@childrens.harvard.edu). ${ }^{2}$ National Center for School Mental Health and Division of Child and Adolescent Psychiatry, University of Maryland School of Medicine, Baltimore, MD, United States of America. ${ }^{3}$ MedStar Georgetown University Hospital, Washington, DC, United States of America. ${ }^{4}$ Massachusetts General Hospital, Boston, Harvard University, Cambridge, MA, United States of America. ${ }^{5}$ Department of Primary Care and Mental Health, University of Liverpool, Liverpool, United Kingdom. ${ }^{6}$ Regional Advisor for Mental Health and Substance Use, WHO Regional Office for the Eastern Mediterranean, Cairo, Egypt

\begin{abstract}
Background: Schools provide an exceptional opportunity for mental health promotion and intervention.

Aims: To describe the development of a World Health Organization (WHO) mental health in schools programme in the Eastern Mediterranean Region.

Methods: Two tenets guided development of the mental health in schools programme: (1) it used a multitiered system of support framework that includes 3 tiers of interventions (universal, early and targeted); and (2) interventions that must be feasible for implementation by non-mental health professionals.

Results: The WHO mental health in schools programme manual is organized into a background section, followed by 3 modules: social-emotional childhood development; mental health promoting schools (promotion and prevention); and addressing student mental health problems in your classroom, including specific classroom strategies and case examples.

Conclusion: Developing an appropriate curriculum that is sensitive to the needs of individual countries requires involvement of those familiar with schooling in those countries. It should include mental health priorities and practices that promote mental health, and coalesce school staff, parents and community members in support of their children.

Keywords: Eastern Mediterranean Region, implementation science, school, public health, mental health

Citation: Hamoda HM; Hoover S; Bostic J; Rahman A; Saaed K. Development of a World Health Organization mental health in schools programme in the Eastern Mediterranean Region. East Mediterr Health J. 2022;28(3):225-232 https://doi.org/10.26719/emhj.22.022

Received: 05/05/21; accepted: 20/11/21

Copyright ( C World Health Organization (WHO) 2022. Open Access. Some rights reserved. This work is available under the CC BY-NC-SA 3.o IGO license (https://creativecommons.org/licenses/by-nc-sa/3.o/igo)
\end{abstract}

\section{Introduction}

There is an urgent need to address mental health issues among children and adolescents. Approximately 1 in 5 children globally (1) and 90\% of children living in low- and middle-income countries (LMICs) struggle with a mental illness (2). The World Health Organization (WHO) Eastern Mediterranean Region (EMR), comprising 22 countries, has a large portion of its population under the age of 18 years. Several countries in the EMR have experienced complex humanitarian emergencies including wars, displacement and political unrest. Children exposed to such conflicts have been known to experience higher rates of mental health problems. Investing in the mental health of children should therefore be a national priority with long-term implications for these countries. Despite this reality, the EMR has a striking deficit of mental health resources for young people (3) and regional collaboration among countries on child and adolescent mental health has been challenging (4). Therefore, innovative implementation strategies are necessary to scale-up mental health services in LMICs (5).

In the face of these challenges, the WHO Regional Office for the Eastern Mediterranean (WHO EMRO) has proposed a regional framework to scale-up action on mental health in the Region (6). This framework was adopted by Member States at the 62nd Session of the WHO Regional Committee for the Eastern Mediterranean held in Kuwait, 5-8 October 2015. The framework identified high impact, cost-effective, affordable and feasible strategic actions supported by a set of indicators to monitor implementation. As part of this framework, school mental health services were identified as a priority area for mental health promotion and practice (7).

There is strong evidence to support investment in mental health in schools. School experiences are critical for children's development and mental health. Emotional health and academic achievement have been strongly associated (8). Schools can enhance academic achievement by addressing issues such as self-esteem and social well-being (9). Children with emotional problems are more prone to poor academic performance and for dropping out of school, making them more vulnerable to a variety of problems including substance abuse, criminal/ legal involvement and exploitation (10). Addressing mental health in schools has important implications for teachers as well as students (11).

Comprehensive school mental health systems encourage school and community staff, including educators and health and mental health professionals, to offer multitiered systems of 
supports (MTSSs), from mental health promotion to treatment in schools (12). We recognize the wide variation in the EMR in terms of resources and capacity for such systems. As a consequence of the dearth of child mental health specialists such as psychiatrists and psychologists, schools in LMICs often task-shift mental health support to educators $(13,14)$. The purpose of this paper is to describe the development of a WHO programme for mental health in schools, catering to the needs of a wide variety of school systems in the EMR, including a review of implementation challenges and opportunities.

\section{Methods}

\section{WHO EMRO mental health in schools programme development}

Child mental health was highlighted as a priority in the WHO EMRO Framework for Mental Health (6) and mental health in schools was identified as an attractive, feasible, cost-effective option. In response to this directive, WHO EMRO commissioned a systematic review of school mental health interventions to inform the development of a WHO mental health in schools programme. The development process, initially led by a child and adolescent psychiatrist working in partnership with the WHO EMRO, involved a review of literature on school mental health frameworks and interventions, and consultation with international school mental health leaders. The goal was to identify core features of effective and culturally sensitive school mental health and specific interventions that could feasibly be implemented with available resources in EMR schools.

Based on a review of the literature and expert consultation, 2 tenets guided WHO development of the mental health in schools programme: (1) the WHO mental health in schools programme should be implemented using an MTSS framework including 3 tiers of interventions (universal mental health promotion, early intervention, and targeted intervention); and (2) interventions must be easy to implement by non-mental health professionals, including educators, given the limited number of child mental health specialists in the region.

\section{Three-tiered MTSS}

The WHO has historically advocated a 3-tier model for school mental health (15). Global evidence from programmes such as positive behavior interventions and supports that use a 3-tiered prevention model has demonstrated success in improving academic achievement and successful management of school culture (16, 17), with strong evidence of a positive impact over time (17). Several evidence-based programmes have been successfully implemented in schools across the 3 tiers of support (16). Universal interventions (Tier 1) for all students, regardless of whether at risk for mental health problems, have been shown to promote positive social, emotional and behavioural skills $(18,19)$. Social emotional learning (SEL) programming has been widely adopted in schools, with results demonstrating significantly better SEL competencies and academic performance, and fewer conduct problems, and less emotional distress and substance use problems than students not engaged in SEL $(20,21)$. Secondary interventions (Tier 2$)$, or early interventions, are designed to address mental health concerns for students experiencing mild distress or functional impairment or being at risk for a given problem or concern. Tier 2 interventions in schools, including small group therapies and brief individualized counselling (e.g. motivational interview and problem solving), have been shown to increase student resilience, and decrease the likelihood of engaging in conduct problems and risk behaviours like substance abuse (22). Tertiary interventions (Tier 3) in schools have been shown to treat a variety of mental health problems, including anxiety, depression, post-traumatic stress, disruptive behaviour disorders and substance abuse problems $(23,24)$.

\section{Implementation by non-mental health professionals}

Mental health providers are in short supply worldwide. The EMR similarly has few mental health resources for young people, including a lack of mental health providers, facilities, training and awareness programmes, and many countries lack adequate mental health policies and laws (25). This underlies the need for integration of mental health across other child service sectors beyond existing health services (26). Schools are among the most feasible and important sites to promote child mental health. While approximately $15 \%$ of children experience mental health problems (27), less than half actually receive treatment even in the most-well-resourced countries. Of those children receiving mental health treatment, > 75\% receive it at schools, since obtaining mental health treatment outside of schools is often expensive, not available in some areas, and can overwhelm families (28).

Based on these 2 guiding principles, and the review of core school mental health features and MTSS interventions in schools, an initial draft of the WHO mental health in schools programme manual was developed via an international, multisectoral, iterative process. The manual development team included perspectives from regional and international experts as well as expertise from the healthcare and education sectors. Experts involved in the development and review process included the directors of leading international centres on mental health in schools like the National Center for School Mental Health at the University of Maryland School of Medicine (www.schoolmentalhealth. org) and the School Psychiatry Program at Massachusetts General Hospital, as well as school mental health leaders from several EMR countries. There were 6 developers and reviewers from the United States of America (USA), 4 from WHO, 2 each from Oman, Bahrain, Canada and the United Kingdom of Great Britain and Northern Ireland (UK), and 1 each from Egypt, Palestine, Saudi Arabia and Ethiopia. These experts came from multiple 
disciplines: 14 were experts in school mental health, school health, public health and implementation science; 4 WHO staff; 3 experts in education; and 1 person from a nongovernmental organization. The manual was presented to a consultative meeting involving experts at WHO EMRO in December 2014 for review and scale-up plans. Following the first regional WHO mental health in schools programme training conducted in Amman in May 2016, further revisions were made based on participant feedback.

\section{Results}

\section{WHO mental health in schools programme}

Review of existing school mental health literature, iterative expert input, and participant feedback from the pilot training of education and behavioural health leaders from EMR countries informed the development of the WHO mental health in schools programme. The resulting document focuses on prevention and promotion, fostering a positive culture in schools, early identification and referral, as well as tiered interventions that can be applied by teachers within a classroom setting. Interventions are grouped under 3 tiers for primary, secondary and tertiary interventions. The programme includes a 103-page reference manual, training materials and handouts, as well as adaptation, implementation, evaluation and monitoring guidance.

WHO mental health in schools programme tiers were defined as follows: Tier 1: focus on mental health promotion or primary prevention and applied to whole populations (e.g. all of the students in a classroom). Tier 2: interventions targeting specific vulnerable populations (e.g. children who have experienced potentially traumatic events). They can also be applied when Tier 1 interventions have not been effective. Tier 3: interventions aimed at supporting children with diagnosed disorders or when Tier 2 interventions have been ineffective. Realizing that mental health is an inseparable part of overall health, topics like nutrition, physical activity in schools, vision, hearing and speech are covered. The programme also addresses contemporary topics like screen time, internet addiction and cyberbullying.

The mental health in schools programme emphasizes evidence-based strategies that can be implemented at low-cost and at scale, incorporating key principles of task-shifting for non-specialists. Included are guidelines for universal and targeted strategies addressing common emotional and behavioural problems, including sadness, anxiety, suicidal thoughts, attention problems and post-traumatic reactions. The manual is designed for use by non-mental health specialists including teachers, administrators, school nurses, social workers, and school counsellors. The manual is intended for a nonclinical audience and avoids using specific diagnostic classifications such as major depressive disorders or posttraumatic stress disorder, and instead uses terms like depression/sadness problems and post-trauma problems. All materials were supplemented with illustrations, to ensure that they reflected the diversity that exists in the EMR.

The WHO mental health in schools programme is organized into a background section conveying the importance of mental health in schools, followed by three modules: social-emotional childhood development, mental health promoting schools (promotion and prevention), and addressing student mental health problems in your classroom (and when to refer for additional help), and a set of appendices with supplemental materials (Table 1). The course includes specific classroom strategies and case examples to reinforce skill application to common classroom scenarios.

\section{WHO SMHP feasibility and acceptability}

At its launch, 38 master trainers in the mental health in schools programme were trained from Bahrain, Egypt, Islamic Republic of Iran, Jordan, Morocco, Oman, Pakistan, Qatar and Saudi Arabia. Beyond the first cohort of trainees, further cascade training has been conducted in Bahrain, Egypt, Islamic Republic of Iran, Jordan, Pakistan and United Arab Emirates, and has included 2139 master trainers (see Table 2 for further information). Besides being available in English, the programme has been translated into several regional languages including Arabic, Farsi and Urdu.

In 2016, the School Mental Health Implementation Network in the EMR (SHINE) was formed with the aim of scaling up the WHO EMRO mental health in schools programme in the Region by enhancing collaboration among practitioners, researchers and policy-makers (29). The network includes partners from academia, nongovernmental organizations, policy-makers, and implementation scientists from Egypt, Islamic Republic of Iran, Jordan and Pakistan, with support from international universities including Liverpool in the UK and Harvard, Johns Hopkins and the University of Washington in the USA. The SHINE network is funded by the US National Institute of Mental Health (NIMH).

Pilot studies have indicated that the WHO mental health in schools programme is acceptable and feasible. One study in an inner-city school setting in Lahore, Pakistan investigated teachers' perceptions about students' mental health. Teachers identified the most common problems they face as learning problems, inattention, disobedience, aggression, lying and disrespect, with few identifying emotional difficulties (30). Another study conducted in Al-Obour City, Egypt provided evidence that delivery of the school-based mental health programme was acceptable to key stakeholders if they were well trained and supported. In another pilot randomized controlled trial, the effectiveness of the mental health in schools programme in improving teachers' mental health literacy as compared to a waitlist control group (not receiving training during the study period) is being examined (31).

A key focus of SHINE is to address challenges to scale up the mental health in schools programme especially in the lesser-resourced countries. Stakeholders have 
Table 1 Content summary of the mental health in schools programme manual

\begin{tabular}{|c|c|}
\hline \multirow[t]{2}{*}{ Background } & Topics covered \\
\hline & Importance of school mental health \\
\hline \multirow[t]{6}{*}{ Module 1} & Social-Emotional Childhood Development \\
\hline & 1.1. Developmental tasks of preschoolers \\
\hline & $\begin{array}{l}\text { 1.2. Developmental tasks of primary-school-age children } \\
\text { (6-12 years) }\end{array}$ \\
\hline & $\begin{array}{l}\text { 1.3. Developmental tasks of secondary-school-age } \\
\text { children (12-18 years) }\end{array}$ \\
\hline & 1.4. Moral development \\
\hline & Brain development and schooling \\
\hline \multirow[t]{17}{*}{ Module 2} & Mental-Health-Promoting Schools (Promotion and Prevention) \\
\hline & 2.1 Core values of a mental-health-promoting school \\
\hline & 2.1.1 Role of parents in their child's education \\
\hline & 2.2 Behavioral management strategies for schools \\
\hline & 2.2.1 Discipline and management of disruptive behavior \\
\hline & 2.2.2 Counseling \\
\hline & 2.2.3 Circle time \\
\hline & 2.3 Life skills education \\
\hline & $\begin{array}{l}\text { 2.4 Other Health-promoting efforts that impact mental } \\
\text { health }\end{array}$ \\
\hline & 2.4.1 Nutrition \\
\hline & 2.4.2 Vision/hearing/speech \\
\hline & 2.4.3 Physical exercise \\
\hline & 2.5 Media and mental health \\
\hline & 2.5.1 Screen time \\
\hline & 2.5.2 Internet addiction \\
\hline & 2.5.3 Cyber bullying \\
\hline & 2.6 Suicide prevention \\
\hline
\end{tabular}

Module 3

Addressing Student Mental Health Problems in Your Classroom (and when to refer for additional help)

3.1 When to refer to a specialist for evaluation and treatment?

3.2 Roles and responsibilities within the school in regards to mental health

3.3 Behavioral manifestations of common mental health problems and strategies to address them

Anxiety problems

Case study (anxiety)

Case study (separation anxiety/school refusal)

Post-trauma problems

Case study (post-trauma)

Depression or sadness problems - mood stability problems

Case study (depression)

Case study (suicide)

Hyperactivity, impulsivity and inattention problems

Case study (ADHD/disruptive behaviors)

Developmental problems

Case study (autism)

Psychosis

Case Study (psychosis)

Oppositional problems/conduct problems

Case study (conduct disorders)

Case study (bullying)

Substance use problems

Case study (substance abuse)

References

Appendix

Appendix I - Teacher Wellness

Appendix II - Risk and Protective Factors for Mental Illness

Appendix III - Bullying Prevention and Intervention in Schools

Appendix IV - Examples of School Intervention Programs from the Eastern Mediterranean Region Appendix V - Screening Tools That Can Be Used at Schools Appendix VI - Resources

identified training and supervision of teachers at scale, maintaining their motivation, and engaging parents as key hurdles. In Pakistan, the WHO mental health in schools programme has been enhanced by developing an interactive online training programme integrated into teachers' continuing education platforms (32). Teachers' wellness and parental engagement have been emphasized and operationalized. Teachers use an interactive chat-bot 


\begin{tabular}{lcc}
\hline \multicolumn{3}{l}{ Table 2 Training on the mental health in schools programme } \\
in various countries \\
\begin{tabular}{lcc} 
Country & Number of trainees & Number of schools \\
\hline Bahrain & 32 & 20 \\
Egypt & 356 & 68 \\
Iran & 270 & 18 \\
Jordan & 150 & 104 \\
Pakistan & 368 & 90 \\
UAE & 963 & 353 \\
Total & 2,139 & 653 \\
\hline
\end{tabular}
\end{tabular}

${ }^{a}$ A modified version of the program was used for trainings in some schools in Pakistan.

on a smartphone to work with children in classroom settings. Didactic information can be taped and archived to be provided to school staff, because they can engage in the programme, so that consultation and supervision can more readily occur, and that monitoring impacts through simple data collection (attendance, disciplinary reports, etc.) may be enhanced. In addition, such online programmes are highly adaptable to meet emerging needs such as the COVID-19 pandemic (33). Currently, a cluster randomized trial is taking place in Pakistan where the mental health in schools programme is being evaluated in 80 schools and involving 960 students (34).

\section{Discussion}

Schools provide an exceptional opportunity for mental health promotion and interventions. In this study, we described the process of developing a WHO mental health in schools programme in the EMR, including challenges and opportunities.

Several reasons favour mental health promotion being implemented within EMR schools. First, schools provide the best opportunity to address the highest number of children, as most children attend school. Second, the programme focuses on using teachers to provide mental health support to children. Teachers are familiar with child development, and well positioned to promote positive mental health practices. Teachers are well respected and well received by most families, so instruction in health, including mental health, from teachers is often acceptable to families. Third, teachers recognize the importance of mental health in the classroom, and respond to programmes that empower them to recognize and address mental health concerns that affect children's performance. The provision of mental health literacy for teachers in under-resourced areas increases teachers' understanding and awareness of students' mental health, while significantly decreasing stigma associated with mental illness (35). Fourth, teachers are positioned to continuously adapt relevant content to the changing concerns that emerge.

The development of mental health in schools programme revealed several opportunities for creating a viable mental health programme for diverse countries in the same region.

1) While EMR countries share commonalities including cultural heritage and religion, they also all have distinct identities and differences. There are multiple challenges in designing regional programmes to be implemented in settings that have variability in resources and sociodemographic realities. Some EMR countries are among the wealthiest in the world while others are among the poorest (e.g. the 2018 GDP per capita in Qatar was $\$ 69026$ compared to $\$ 498$ in Somalia). The WHO mental health in schools programme responded to this challenge by providing a list of interventions over multiple tiers that involve a wide range of resource utilization. In regard to variability in cultural and ethnographic realties, the programme has a framework to allow adaptations for different implementation settings. Engaging representatives from many EMR countries helped clarify common priorities as well as different needs.

2) EMR countries face different challenges (e.g. with some experiencing more trauma exposure). Some topics were included that may be higher in priority to specific countries than others, recognizing that individual tailoring is needed during implementation. With limited evidence of school mental health intervention in LMICs (19), developers acknowledged that some of the recommended interventions may not be generalized to all EMR countries or schools.

3) Content development presented unique challenges related to questions about what and how much to include, and how to generalize findings from non-EMR settings. For example, one challenge in developing the programme content was the tension between depth and breadth (i.e. should more topics be covered or should the focus be on having fewer topics covered in greater depth?). Consideration was also given to the balance between including necessary components and not overburdening often overworked, stressed teachers.

4) The WHO mental health in schools programme recognizes the importance of parental support and participation. While the programme primarily targets educators and not students directly, interventions highlighted parent participation, and the WHO EMRO has also developed a life skills programme for students. Programmes directly targeting teachers may be best complemented with those that also target students, such as life skills education and those targeting parents in supporting the emotional needs of children.

5) Continued engagement across EMR countries remains important for revising and enhancing the WHO mental health in schools programme. Mutually beneficial, cooperative agreements between countries to evaluate components of the programme and interventions will accelerate refinements and implementation factors important for the programme's 
success. The establishment of the SHINE network will contribute to evidence from LMICs and provides a foundation and network for groups and countries from the EMR and beyond. SHINE provides a vehicle for countries to identify practices that have the greatest impact and are aligned with available resources within these countries.

6) Building bridges of collaboration between the education and healthcare systems is necessary for the success of the mental health in schools programme. Encouraging co-ownership of school mental health programmes allows both sectors to work collaboratively rather than alone. Adaptation of the programme to local needs will increase the sense of ownership.

7) Scaling up a school-based mental health programme remains an important focus from its inception. Multiple challenges need to be anticipated so that viable solutions can be considered and configured as the programme is expanded. Using simple available technology in digitalizing the program will helps in these scale-up efforts.

\section{Conclusions}

For the foreseeable future, most countries will lack sufficient resources to address their mental health needs. Mental health in schools programmes provide an immediate opportunity for improving mental health and decreasing the many burdens of poor mental health. Development of an appropriate curriculum sensitive to the needs of individual countries requires involvement of those familiar with schooling, current mental health priorities, and which strategies and practices would be embraced to promote mental health, and bring together school staff, parents and community members in support of their children. Technological innovations are essential in scale-up efforts for training and supervision. Finally, establishing monitoring and evaluation metrics and allowing learning among countries, as in the SHINE network, will help ensure sustainability.

Funding: None.

Competing interests: None declared.

\section{Mise en place d'un Programme de l'Organisation mondiale de la Santé pour la santé mentale en milieu scolaire dans la Région de la Méditerranée orientale}

\section{Résumé}

Contexte : Les écoles offrent une occasion exceptionnelle de promotion de la santé mentale et d'intervention dans ce domaine.

Objectifs : Décrire la mise en place d'un Programme de l'Organisation mondiale de la Santé (OMS) pour la santé mentale en milieu scolaire dans la Région de la Méditerranée orientale.

Méthodes: Deux principes ont guidé l'élaboration d'un Programme de santé mentale en milieu scolaire: 1) Le programme a utilisé un système de cadre d'appui à plusieurs niveaux comprenant trois niveaux d'interventions (universel, précoce et ciblé) ; et 2) les interventions doivent pouvoir être mises en œuvre par des personnes qui ne sont pas des professionnels de la santé mentale.

Résultats: Le manuel du Programme OMS pour la santé mentale en milieu scolaire est organisé de la manière suivante: il comprend une section de base, suivie de trois modules : développement social et émotionnel de l'enfant; promotion de la santé mentale dans les écoles (promotion et prévention); et résolution des problèmes de santé mentale des élèves dans la classe, y compris des stratégies spécifiques en classe et des exemples de cas.

Conclusion: L'élaboration d'un programme d'études approprié et adapté aux besoins de chaque pays nécessite l'implication de ceux qui connaissent bien la scolarité dans ces pays; ce processus qui exige la mobilisation du personnel scolaire, des parents et des membres de la communauté au service de leurs enfants, devrait prendre en compte les pratiques qui favorisent la santé mentale et les priorités dans ce domaine.

$$
\begin{aligned}
& \text { إعداد برنامج منظمة الصحة العالمية للصحة الثفسية الملدرسية في إقليم شرق المتوسط } \\
& \text { هشام حمودة، شارون هوفر، جيف بوستيك، عاطف الرحن، خالد سعيد } \\
& \text { الخالاصة } \\
& \text { الخلفية: تتيح المدارس فرصة متازة لتعزيز الصحة النفسية وتدخلاتها. } \\
& \text { الأهداف: هدفت هذه الدراسة إلى وصف عملية إعداد برنامج منظمة الصحة العالمية للصحة النفسية المدرسية في إقليم شرق المتوسط. }
\end{aligned}
$$

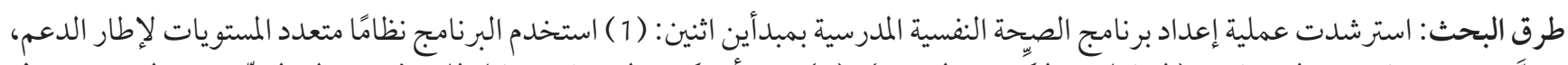

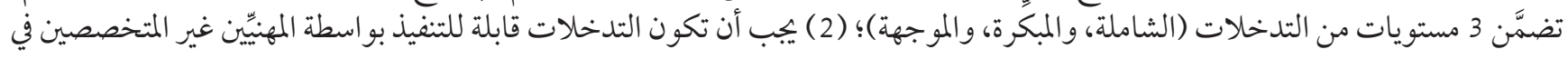

$$
\begin{aligned}
& \text { بجال الصحة النفسية. }
\end{aligned}
$$




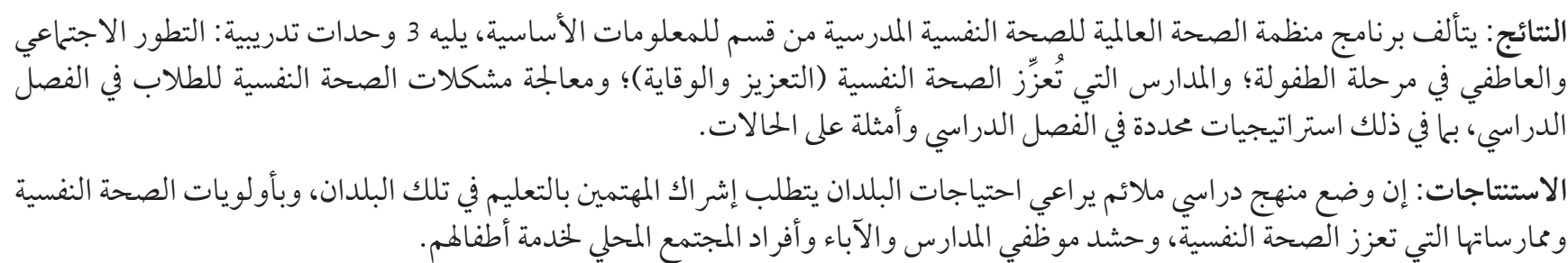

\section{References}

1. Merikangas KR, He J-P, Burstein M, Swanson S, Avenevoli S, Cui L, et al. Lifetime prevalence of mental disorders in U.S. adolescents: results from the National Comorbidity Survey Replication--Adolescent Supplement (NCS-A). J Am Acad Child Adolesc Psychiatry. 2010 Oct;49(10):980-9. https://doi.org/10.1016/j.jaac.2010.05.017 PMID:20855043

2. Kieling C, Baker-Henningham H, Belfer M, Conti G, Ertem I, Omigbodun O, et al. Child and adolescent mental health worldwide: evidence for action. Lancet, 2011 Oct 22;378(9801):1515-25. https://doi.org/10.1016/So140-6736(11)60827-1 PMID:22008427

3. Rahman A, Hamoda HM, Movaghar AR, Khan M, Saeed K. Mental health services for youth in the Eastern Mediterranean Region: challenges and opportunities. East Mediterr Health J. 2019 Mar 19;25(2):80-1. https://doi.org/10.26719/2019.25.2.80 PMID:30942470

4. Hamoda HM, Belfer ML. Challenges in international collaboration in child and adolescent psychiatry. J Child Adolesc Ment Health. 2010 Dec;22(2):83-9. https://doi.org/10.2989/17280583.2010.528577 PMID:25859766

5. Naslund, J, Kalha, J, Restivo, JL, Amarreh I, Callands T, Chen H et al. Identifying challenges and practical solutions for global mental health implementation research: a key informant study of the National Institute of Mental Health Scale-Up Hubs. Asian J Psychiatry. 2021 Mar;57:102577. https://doi.org/10.1016/j.ajp.2021.102557 PMID:33561780

6. Regional framework to scale up action on mental health in the Eastern Mediterranean Region [website]. Cairo: World Health Organization Regional Office for the Eastern Mediterranean; 2016 (https://applications.emro.who.int/dsaf/EMROPUB_2016_ EN_18700.pdf, accessed 6 January 2022).

7. Barry MM, Clarke AM, Petersen I. Promotion of mental health and prevention of mental disorders: priorities for implementation. East Mediterr Health J. 2015 Sep 28;21(7):503-11. https://doi.org/10.26719/2015.21.7.503 PMID:26442891

8. Kase C, Hoover S, Boyd G, West K, Dubenitz J, Trivedi P, et al. Educational outcomes associated with school behavioral health interventions: a review of the literature. J Sch Health 2017 Jul;87(7):554-62. https://doi.org/10.1111/josh.12524 PMID:28580676

9. Hattie JAC. Visible learning: a synthesis of over 800 meta-analyses relating to achievement. New York: Routledge; 2009.

10. Edalati H, Nicholls TL, Crocker AG, Roy L, Somers J, Patterson M. Adverse childhood experiences and the risk of criminal justice involvement and victimization among homeless adults with mental illness. Psychiatr Serv 2017 Dec 1;68(12):1288-95. https://doi. org/10.1176/appi.ps.201600330 PMID:28859582

11. Fisher MH. Factors influencing stress, burnout, and retention of secondary teachers. Curr Issues Educ. 2011;14(1).

12. Advancing comprehensive school mental health: guidance from the field [website]. Baltimore: National Center for School Mental Health, University of Maryland School of Medicine; 2019 (https://www.schoolmentalhealth.org/Resources/Foundationsof-School-Mental-Health/Advancing-Comprehensive-School-Mental-Health-Systems--Guidance-from-the-Field/, accessed 6 January 2022).

13. Fazel M, Hoagwood K, Stephan S, Ford T. Mental health interventions in schools in high-income countries. Lancet Psychiatry. 2014 Oct;1(5):377-87. https://doi.org/10.1016/S2215-0366(14)70312-8 PMID:26114092

14. Fazel M, Patel V, Thomas S, Tol W. Mental health interventions in schools in low-income and middle-income countries. Lancet Psychiatry. 2014 Oct 1;1(5):388-98. https://doi.org/10.1016/S2215-0366(14)70357-8

15. Hendren R, Birrell Weisen R, Orley JH. Mental health programmes in schools. Geneva: World Health Organization; 1994 (https:// apps.who.int/iris/handle/10665/62308, accessed 6 January 2022).

16. Murphy JM, Abel MR, Hoover S, Jellinek M, Fazel M. Scope, scale, and dose of the world's largest school-based mental health programs. Harv Rev Psychiatry. 2017 Sep/Oct;25(5):218-28. https://doi.org/10.1097/HRP.0000000000000149 PMID:28787304

17. Horner RH, Sugai G, Smolkowski K, Eber L, Nakasato J, Todd A, et al. A randomized, waitlist controlled effectiveness trial assessing school-wide positive behavior support in elementary schools. J Posit Behav Interv. 2009 Jul 1;11(3):133-44. https://doi. org/10.1177/1098300709332067

18. Abry T, Rimm-Kaufman SE, Larsen RA, Brewer A. The influence of fidelity of implementation on teacher-student interaction quality in the context of a randomized controlled trial of the Responsive Classroom approach. J Sch Psychol. 2013 Aug;51(4):43753. https://doi.org/10.1016/j.jsp.2013.03.001 PMID:23870440

19. Kellam SG, Mackenzie ACL, Brown CH, Poduska J, Wang W, Petras H, et al. The good behavior game and the future of prevention and treatment. Addict Sci Clin Pract 2011 Jul;6(1):73-84. PMID:22003425

20. Durlak JA, Weissberg RP, Dymnicki AB, Taylor R, Schellinger K. The impact of enhancing students' social and emotional learning: a meta-analysis of school-based universal interventions. Child Dev. 2011 Jan-Feb;82(1):405-32. https://doi.org/10.1111/j.14678624.2010.01564.x PMID:21291449 
21. Sklad M, Diekstra R, Ritter MD, Ben J, Graveseteijn C. Effectiveness of school-based universal social, emotional, and behavioral programs: Do they enhance students' development in the area of skill, behavior, and adjustment? Psychol Schools 2012;49(9):892-909. https://doi.org/10.1007/s10212-018-0406-9

22. Lochman JE, Wells KC. The Coping Power program at the middle-school transition: universal and indicated prevention effects. Psychol Addict Behav. 2002 Dec;16(4S):S40-54. https://doi.org/10.1037/0893-164X.16.4s.S40 PMID:12502276

23. Benningfield MM, Riggs P, Stephan SH. The role of schools in substance use prevention and intervention. Child Adolesc Psychiatr Clin N Am. 2015 Apr;24(2):291-303. https://doi.org/10.1016/j.chc.2014.12.004 PMID:25773325

24. Kataoka S, Jaycox LH, Wong M, Nadeem E, Langley A, Tang L et al. Effects on school outcomes in low-income minority youth: preliminary findings from a community-partnered study of a school-based trauma intervention. Ethn Dis 2011 Summer;21(3 Suppl 1):S71-7. PMID:22352083

25. Rahman A. Mental disorders in the Eastern Mediterranean Region. Int J Public Health. 2018 May;63:9-10. https://doi.org/10.1007/ s00038-017-0986-1

26. Patel V, Saxena S, Lund C, Thornicfroft G, Baingana F, Bolton P et al. The Lancet Commission on global mental health and sustainable development. Lancet. 2018 Oct 27;392(10157):1553-98. https://doi.org/10.1016/So140-6736(18)31612-X PMID:30314863

27. Whitney DG, Peterson MD. US national and state-level prevalence of mental health disorders and disparities of mental health care use in children. JAMA Pediatr. 2019 Apr 1;173(4):389-91. https://doi.org/10.1001/jamapediatrics.2018.5399 PMID:30742204

28. Merikangas KR, He JP, Burstein M, Swendsen J, Avenvoli S, Case B, et al. Service utilization for lifetime mental disorders in U.S. adolescents: results of the National Comorbidity Survey-Adolescent Supplement (NCS-A). J Am Acad Child Adolesc Psychiatry. 2011 Jan;50(1):32-45. https://doi.org/10.1016/j.jaac.2010.10.006 PMID:21156268

29. Alonge, OO, Chiumento, AC, Hamoda HM, Gaber E, Huma Z, Abbasinejad M, et al. Identifying pathways for large-scale implementation of a school-based mental health program in the Eastern Mediterranean Region: a theory driven approach. Health Policy Planning 2020 Nov 1;35(Supplement_2):ii112-23. https://doi.org/10.1093/heapol/czaa124 PMID:33156933

30. Imran N, Rahman A, Chaudhry N, Asif A. On the frontline: exploring the perceptions of Lahore's inner-city school teachers regarding children problems. Iran J Public Health. 2018 Oct;47(10):1537-45. PMID:30524984

31. Imran N, Rahman A, Chaudhry N, Asif A. World Health Organization "School Mental Health Manual"-based training for school teachers in Urban Lahore, Pakistan: study protocol for a randomized controlled trial. Trials. 2018 May 24;19(1):290. https://doi. org/10.1186/s13063-018-2679-3 PMID:29793553

32. Hamdani SU, Muzaffar N, Huma Z, Hamdani A, Rauf R, Farzeen M, et al. Using technology to advance school mental health: experience from the Eastern Mediterranean Region. J Am Acad Child Adolesc Psychiatry 2019 Oct 1;58(10):S22. https://doi. org/10.1016/j.jaac.2019.07.095

33. Hamoda HM, Chiumento A, Olakunle A, Hamdani S, Saaed K, Wissow L, et al. The Covid-19 lockdown will have consequences for child mental health: investing in school mental health programs can help. Psychiatr Serv. 2021 Jun;72(6):729-31.

34. Hamdani SU, Warraitch A, Suleman N, Muzzafar N, Minhas FA, Nizami AT, et al. Technology-assisted teachers' training to promote socioemotional well-being of children in public schools in rural Pakistan. Psychiatr Serv. 2021 Jan 1;72(1):69-76. https:// doi.org/10.1176/appi.ps.202000005 PMID:32838678

35. Kutcher S, Wei Y, Gilberds H, Obuguyu O, Njau T, Brown A, et al. A school mental health literacy curriculum resource training approach: effects on Tanzanian teachers' mental health knowledge, stigma and help-seeking efficacy. Int J Ment Health Syst. 2016 Aug 4;10:50. https://doi.org/10.1186/s13033-016-0082-6 PMID:27493684 